\title{
I.M. Pei:
}

Calvin Tsao

I.M. Pei, who lived to an elegant 102 , certainly deserves to be regarded as a legend, and his widely celebrated works validate this claim $[\mathbf{1}, 2]$.

Scholars and critics have observed that I.M. was a committed modernist and that his consistent application of elemental geometries, reductive aesthetics, and purism created the impression of a monumentality that did not trouble itself with the notion of a humanising architectural environment. These observations and impressions are understandable, but 1 believe, somewhat simplistic. I.M.'s version of modernism was not that of the original movement, which had become a didactic methodology of language and form and, by the mid1950s, a globally familiar style. Instead, and never intending to challenge the old guard, I.M. added to the modernist story a new, complementary chapter that infused it with his own worldly interpretation. His work bears an unmistakable cross-cultural pluralism rooted in the Eastern and Western cultural aspects of I.M.'s rich and long life. In this sense, his modernism is deeply mindful of the human condition. Beyond awakening our individual sense of engagement with physical space, he dedicated his work to serving humankind's most ennobling aspirations: enhancing and enlightening our sense of culture, and, most broadly, our sense of humanity and civilisation.

I worked for I.M. from 1980 to 1985 and we remained close friends after. I feel privileged, in that working 'with' him seems the more apt phrase, for being in his presence was much more than just learning an acknowledged master's lessons in architectural philosophy and practice. One story illustrates how time spent with I.M. revealed the

\section{7-2019}
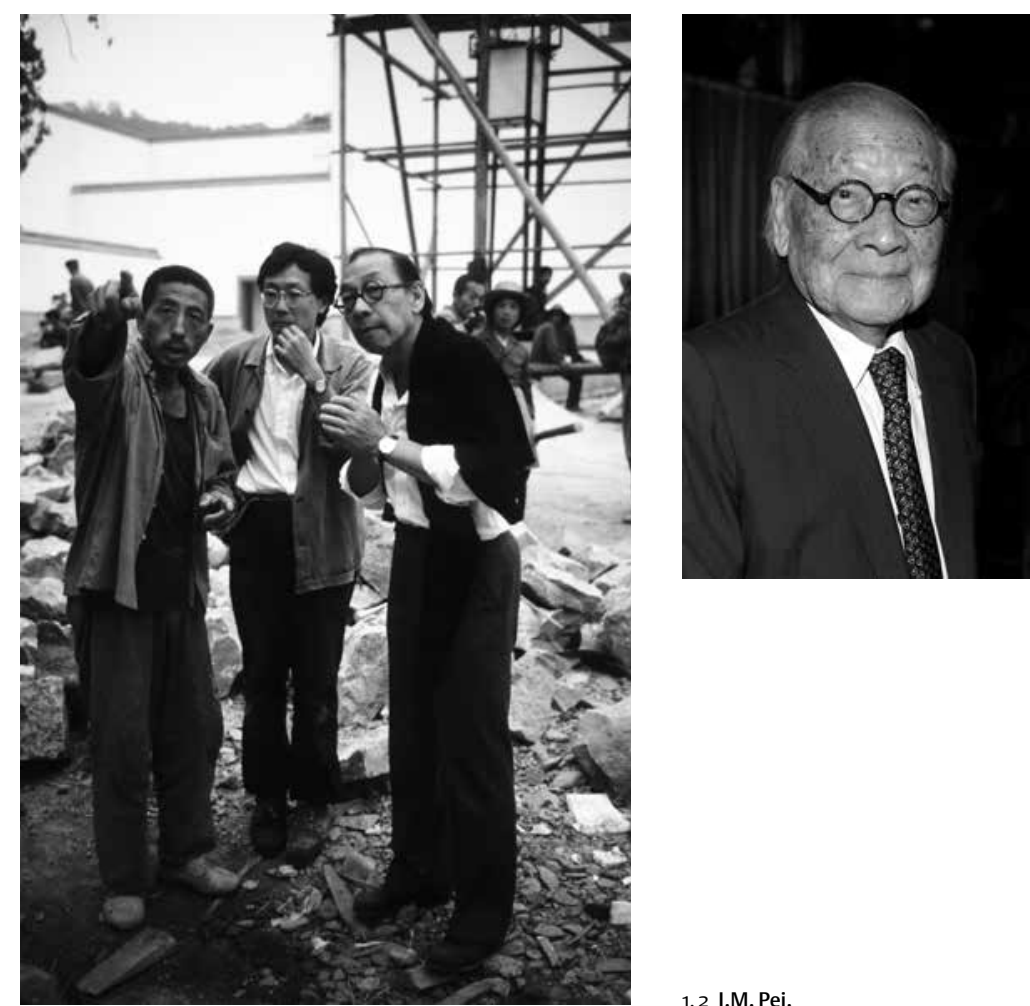

myriad joys of a fully rounded professional and personal life, exuberantly lived: over lunch one day, he explained that creating exquisite architecture is not just executing a grand idea or gesture. Rather, the design process is like that of creating a fine wine. The vagaries of both humans and nature come into play and need to be nurtured with utmost care and patience. Even when aged and finally ready to be drunk, it has to be decanted before it can reveal itself.

For me, I.M. was not only a most generous mentor, but also a father figure whose wisdom, advice, and example helped to inform so many of my own professional and personal perspectives. Working on several of his large projects taught me that great architecture has to be relevant architecture. To conceive and produce it, one begins and maintains a constant positive engagement with circumstances of history, culture, ethics, and social politics. Without these inspirations from I.M., I might never have found the confidence to form and refine my own point of view and then to establish my own practice.

Ieoh Ming Pei began his life in 1917 in Guangzhou, Guangdong (then Canton) province, China, the son of Tsa Yee Pei, a prominent banker. He had a peripatetic early 


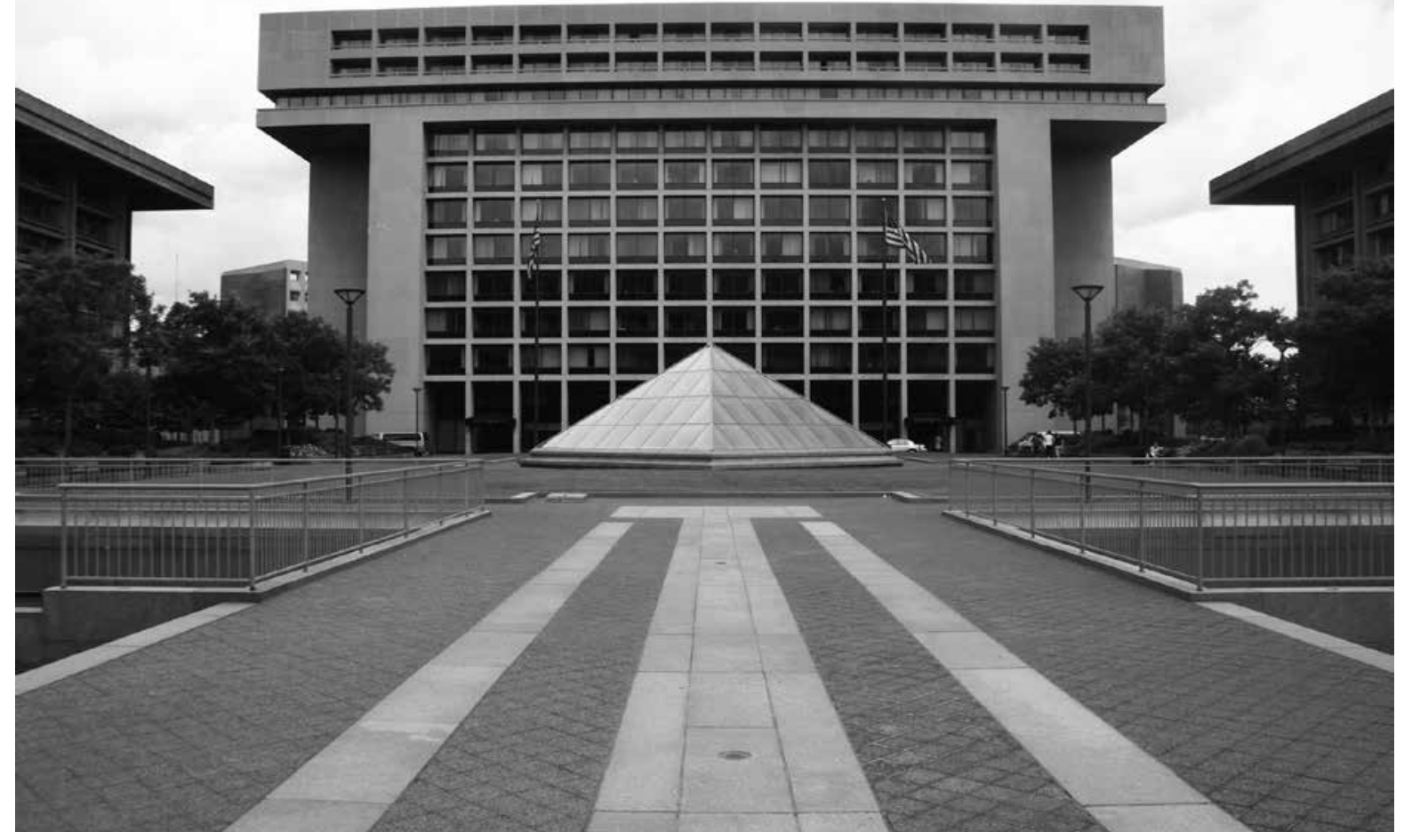

3 L'Enfant Plaza (1965-8).

life as his father took on increasingly important executive positions within the Bank of China. When I.M. was an infant, the bank transferred the family to Hong Kong and, eight years later, they moved again to Shanghai, which had emerged as a politically complex, socially diverse, and cosmopolitan city. As a teenager, I.M. first became captivated by Shanghai's architecture and its impact on social life. As the Peis were educated and affluent, they moved easily among social circles in both cities, integrating Western influences with their deeply ingrained Chinese heritage. I.M. spent his summers in Suzhou, one of China's oldest cultural, intellectual, and commercial centres. His father's family had lived there for five hundred years, and I.M. absorbed and synthesised its many rich facets as a young man, meditating in the family compound known for its ancient garden (the 'Forest of the Lions'). Although the popular fashion for Chinese elites was to attend university in England, I.M. chose to go to the United States, enrolling in the architecture programme at the University of Pennsylvania. However, he found the Classical and Beaux Arts training there static and limiting. He decided to transfer to MIT, where he received his BArch in 1940. By then, China had already begun to face the post-imperial tensions that
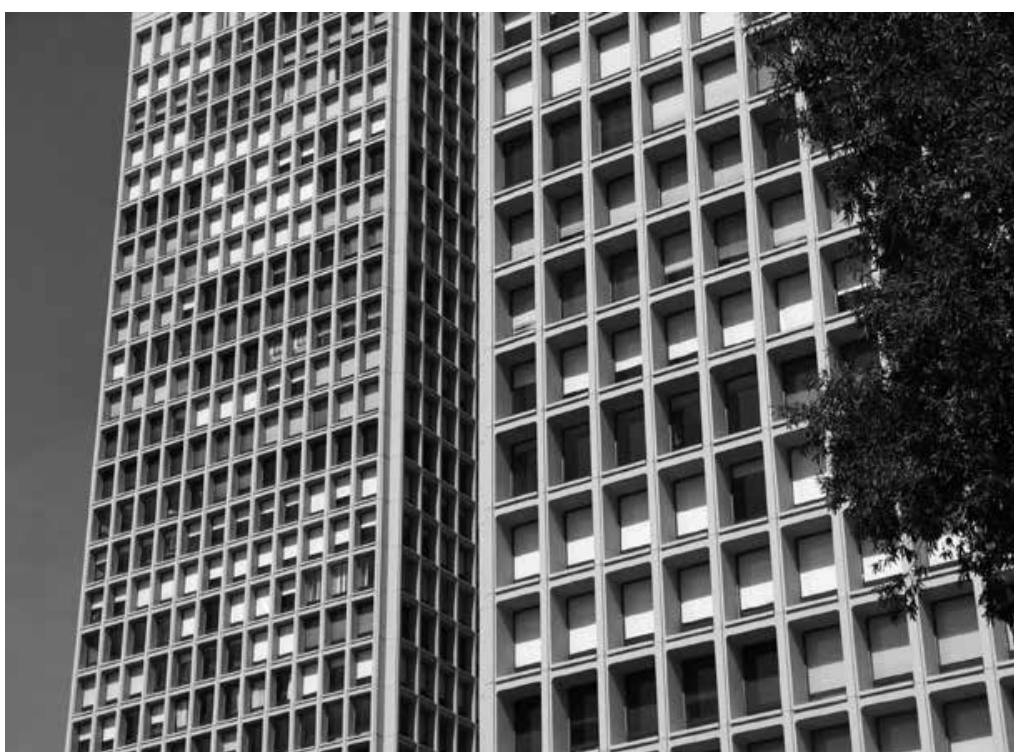

4 Society Hill Towers (1961-4).

would eventually lead to revolution. His family (particularly his father) recommended that he delay his plan to return home and continue his stay in the US.

His decision to stay was fortuitous. He had recently met Eileen Woo, a Chinese compatriot studying at Wellesley. They were an instant match in both background and sensibility, having been raised in similarly distinguished families and now pursuing their passions for architecture. In 1942 they wed - and enrolled together at Harvard's Graduate School of Design (GSD): I.M. in Architecture and Eileen in Landscape Architecture. I know that I.M. held a lifelong view that landscape is an essential foundation for architecture. And I can't help believing that he might have seen the union of husband and wife as a parallel to their chosen disciplines. Either way, the match was meant to be: they were together for more than seventy years. At Harvard, I.M. found his intellectual and aesthetic home. He studied under Walter Gropius and Marcel Breuer, giants of the Bauhaus and, like I.M., arguably refugee-exiles from their birth countries. His MArch and two 


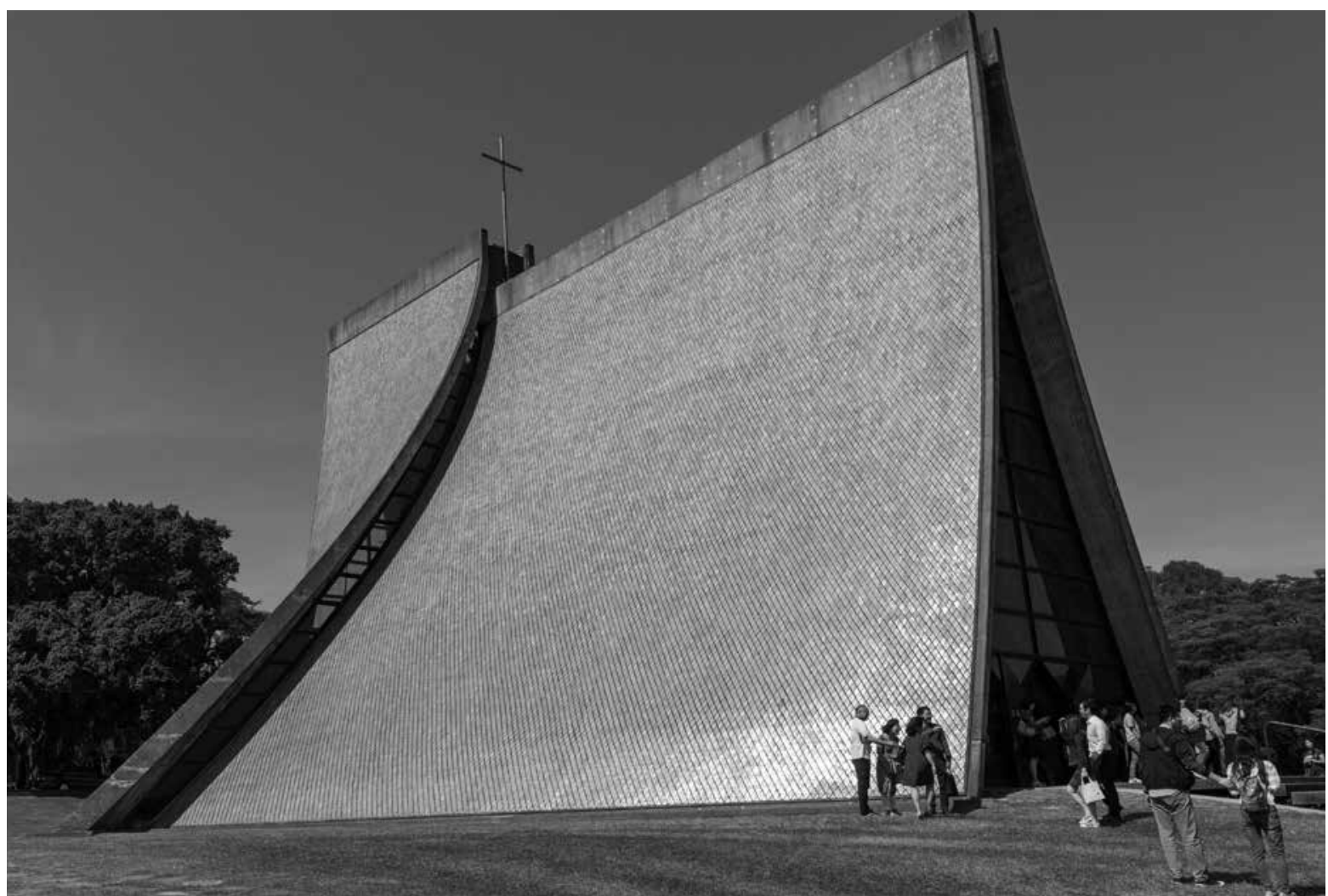

5 Luce Chapel (1962-3)

years' teaching experience at the GSD set the stage for a most unusual yet auspicious start in practice.

In 1949, he was approached by William Zeckendorf of New York, who had just bought the real estate development firm of Webb and Knapp and was seeking a young talent to establish and oversee the firm's in-house architecture capabilities. Although it was rare for a member of our traditionally genteel profession to join the staff of a development company, I.M. found in Zeckendorf an agreeable and rather adventurous colleague. The two shared a belief that modern architecture can improve urban life rather than depersonalise it, and I.M. went on to design such iconic and successful projects as Gulf Oil in Atlanta, Mile High Center in Denver, L'Enfant Plaza in Washington, DC [3], Kips Bay Towers in New York, Society Hill Towers in Philadelphia [4], Place Ville Marie in Montreal, and the Century Towers in Los Angeles - to name a few.

I.M. stayed with Webb and Knapp until 1960, by which time he desired to pursue non-commercial projects outside the Zeckendorf enterprise. Having formed his own firm for this purpose - I.M. Pei \& Associates - he was given Zeckendorf's blessing to work on occasional commissions. First came the 1954 design of the Luce Chapel in Taiwan, a highly

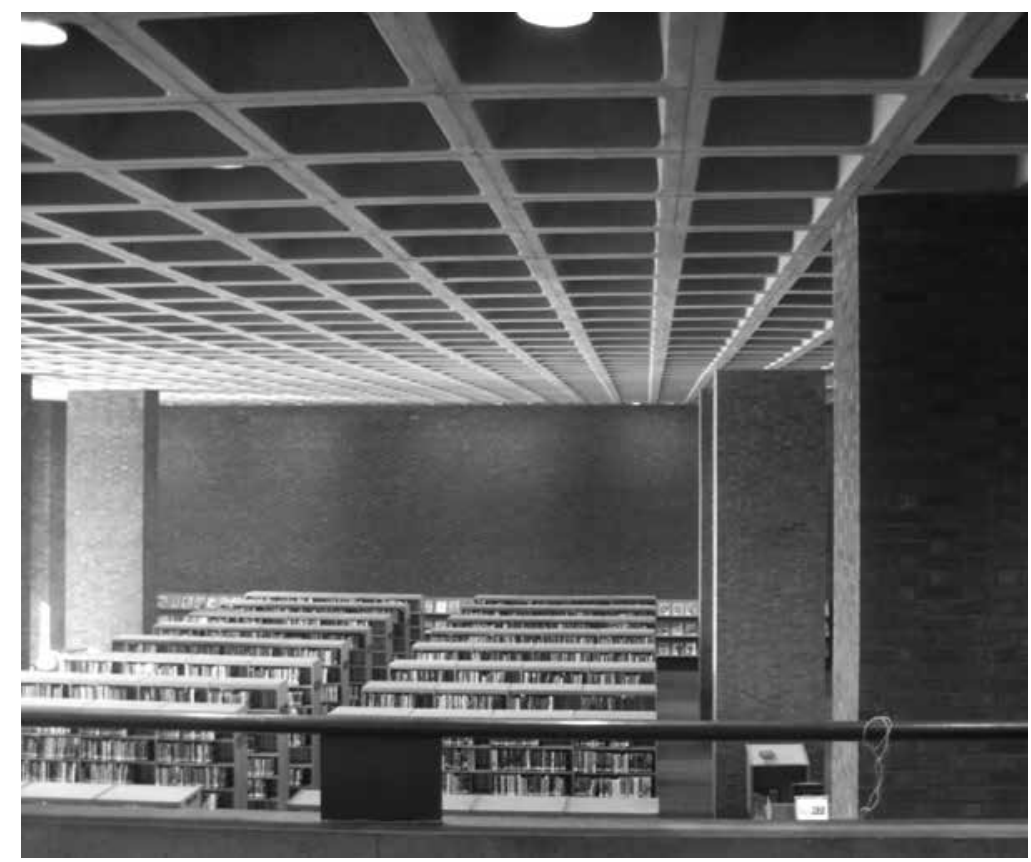

6 Cleo Rogers Memorial Library (1966-9).

poetic piece of architecture that engages complex geometry to evoke a spiritual experience within the space [5]. By the time Luce was completed in 1963, other key projects were also underway, notably the Mesa Laboratory near Boulder, Colorado and MIT's Green Building for earth and atmospheric sciences. He soon spread his wings with diverse commissions both large and small: the Newhouse School at Syracuse University, the Everson Museum of Art in Syracuse, the National Airlines Terminal at John F. Kennedy Airport, and, by contrast, the wonderfully compact Cleo Rogers Memorial Library in Columbus, Indiana [6]. Each of these works proved I.M.'s concern that a project must be relevant to the community it serves and, more 


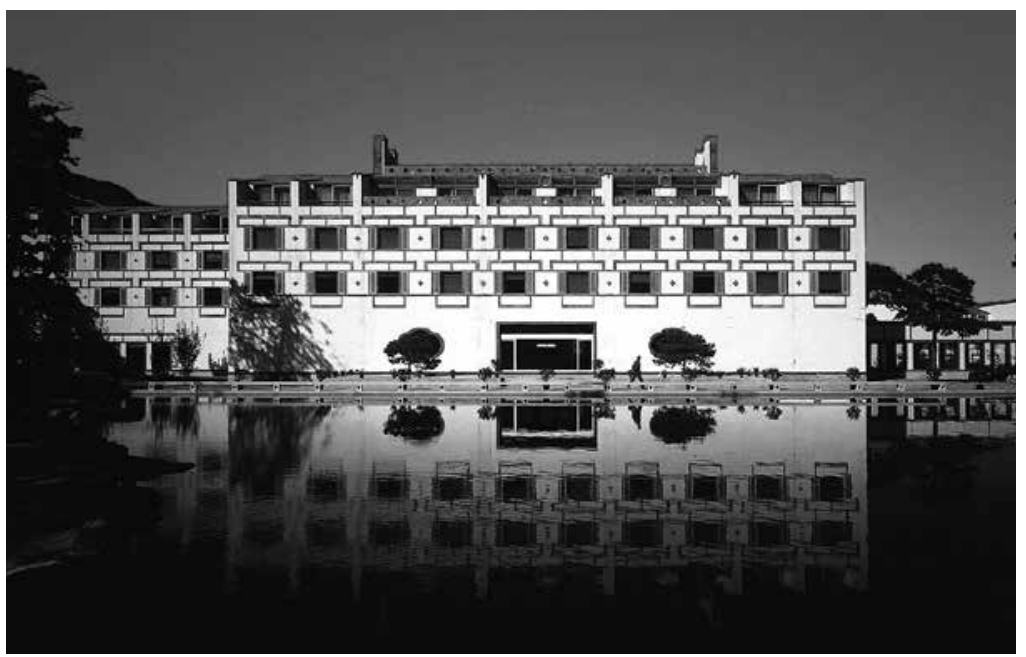

7 Fragrant Hill Hotel (1978-82).

broadly, to social, intellectual, and cultural issues of the day.

Even with this portfolio, it came as something of a surprise when I.M. won what he would later call his most significant project: the John F. Kennedy Library and Museum. I.M. was chosen in 1964 over some of his most formidable peers - Mies van der Rohe, Louis Kahn, Philip Johnson, Paul Rudolf, and Gordon Bunshaft - by Jacqueline Kennedy herself - and perhaps not only because of her informed appreciation of his projects to date. One story goes that, in preparation for Mrs. Kennedy's visit to his office, I.M. discovered that her favourite flower was the chrysanthemum. He filled the reception area with them, and she was noticeably pleased when she arrived. No detail was too small for I.M. For reasons beyond his control, the JFK Library project stalled for nearly ten years in the face of two ultimately insurmountable challenges: community opposition in the originally proposed Cambridge neighbourhood, and a lack of timely cooperation from the Massachusetts Bay Transportation Authority that currently occupied the site. These challenges forced the library to its present location, where, after years of site preparation and construction, it was finally dedicated in 1979.

During these years, the Pei office also grappled with another Boston area project that would cause the firm great distress: the John Hancock Tower. Designed by partner Henry Cobb, Hancock remains a strikingly sleek structure - but one whose realisation tested the limits of material and construction technology. The tower's many familiar flaws had less to do with its architecture than with disastrous engineering failures (falling windows, excessive torsion and swaying, etc.). I.M. and his partners stood firm against blame that was largely misplaced, but the office's reputation suffered a serious setback. Nevertheless, there was also good news along the way, in I.M.'s sensational design for National Gallery of Art, East Building. Completed in 1978, the East Building was I.M.'s first major museum project to gain worldwide acclaim, setting the stage for many later museum commissions.

The 1970 os also brought new international engagements. Following the US's resumption of dialogue with China in 1974, I.M. was invited to join a tour of that country organised by the American Institute of Architects. He had not been back for thirty years and was troubled by what he saw: a country whose architecture was rapidly gravitating away from the rich cultural and historical traditions that he grew up with and cherished. In its place, he saw a bland Soviet-influenced, vaguely contemporary aesthetic that was, at best, indifferent to the wider social and cultural context. His later

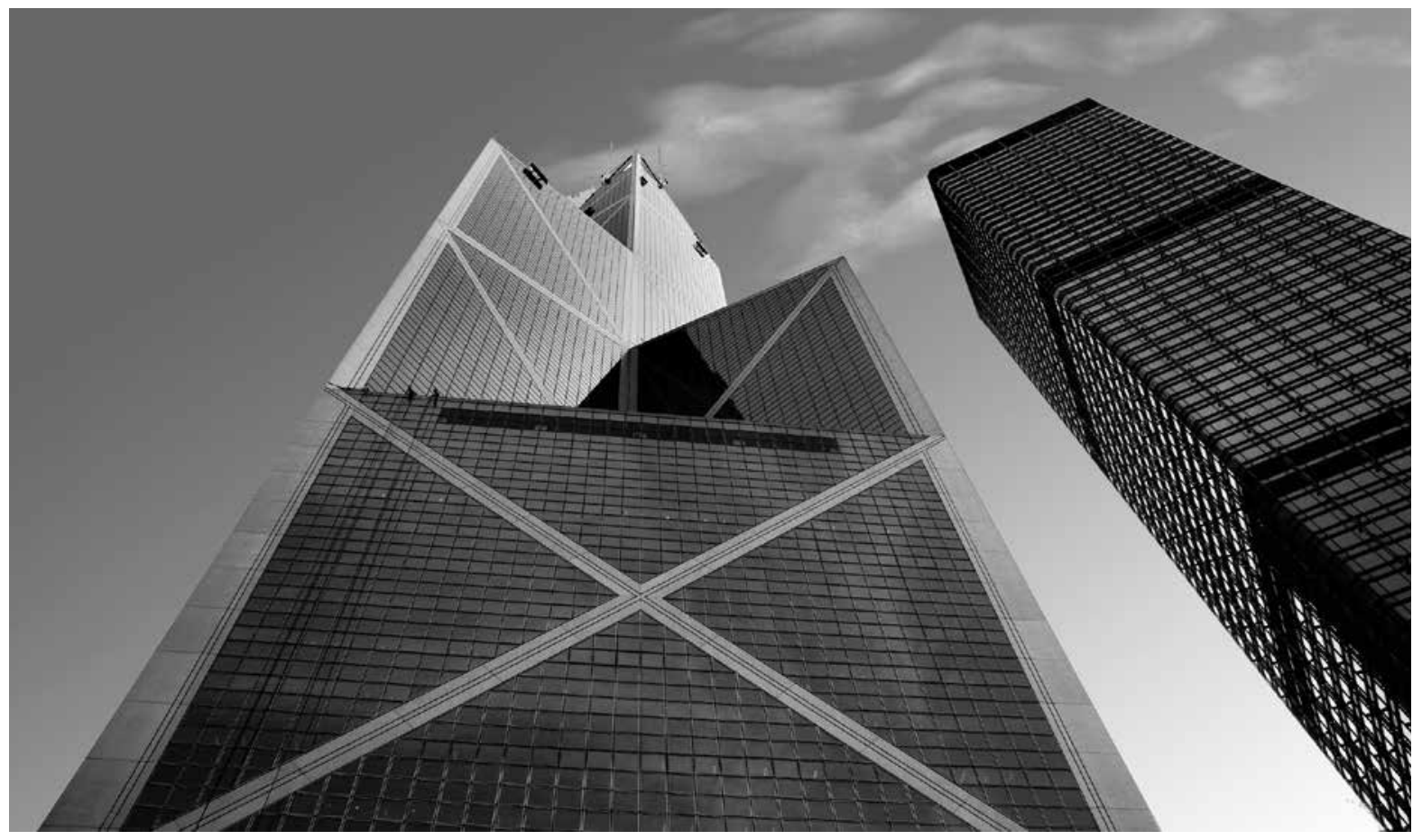

8 Bank of China Tower in Hong Kong (1985-90). 


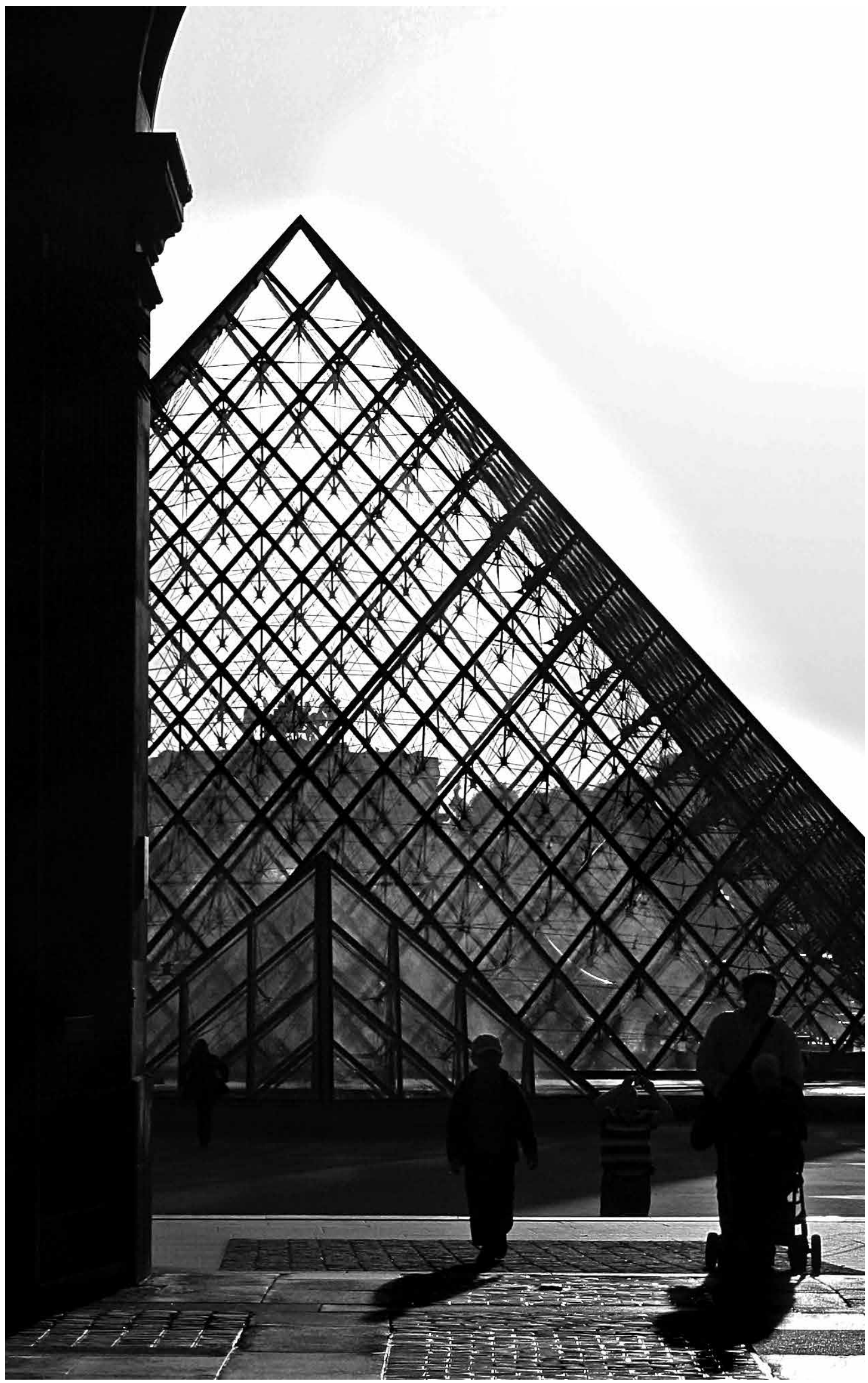

9 Louvre pyramid (1984-9) 
public comments that this was inappropriate to China drew the attention of the Chinese government and, in 1978, President Deng Xiao Ping invited him to visit again and to become the first foreign architect to select and design any project in China that was in the government's plans.

While in Beijing, I.M. first took the opportunity to offer critical urban design advice with respect to the Forbidden City palace compound. He urged the government to adopt zoning rules that would keep building heights low outside the compound, so that a visitor within the compound would not see any contemporary structures - only open sky. This, he argued, would preserve the essential sense of timelessness in the experience. The government agreed and implemented I.M.'s suggestion. As for the project, I.M. was offered several options. Most were large-scale urban office towers or high-rise hotels - but he had other ideas and wanted a special project. While travelling outside of Beijing, he discovered it in a quiet rural district an hour away. The site of a defunct imperial hunting lodge would become the Fragrant Hill Hotel [7]. I.M.'s choice bewildered the government officials; why would a worldfamous architect, born in China but very much of the Western world, want to take on such a modest project in a remote area?

At that time, Pei's grounding in and lifelong appreciation of general classical and vernacular traditions (as in, for example, his Christian Science Center in Boston (1970), which alluded to Greco Roman elements) were little known. Realising that geometry is fundamental to Chinese architecture, I.M. believed that a project in China would enable him to explore and develop an original language connecting the modern architectural vocabulary of our times with the ancient Chinese vernacular traditions that were close to his heart. In this language, manmade volumes and natural landscape in the form of a garden are balanced in harmonious integration. What emerged was a fresh version of the ancient, simple, low-slung courtyard typology. The building's forms were designed around existing landscapes, accommodating existing trees and creating more meditative outdoor spaces. Although administrative complexities and limitations in construction capability frustrated some of I.M.'s intentions, Fragrant Hill established itself as the iconic early expression of his approach toward building in China.

Fragrant Hill was but the first of many storied projects in Asia.

Applying his language to a broader set of typologies, I.M. achieved remarkable results, most notably the Bank of China Tower in Hong Kong (1989) [8]. A rigorously geometric structure, the building has a square plan divided diagonally into four triangular sections forming volumes that top off at twelve, twenty-four, thirty-six, and seventy-two storeys (full height). And yet, this rigour also evokes the tower's metaphorical cultural underpinning - the poetic image of shimmering bamboo shoots after the rain, as in the Chinese haiku, in which each shoot 'rises ever higher incrementally'. The building is not merely the product of geometry; it deploys geometry in the expression of shared cultural mythologies. The same approach is evident in several later projects, including the Beijing headquarters of the Bank of China (1999) and the Suzhou Museum in his hometown (2006).

I.M.'s technique of both deriving from and deploying geometry is the essence of the most controversial, but ultimately most recognisable and celebrated commission of his career: the Louvre pyramid [9]. Iconic, ancient, and mystical, the pyramidal form had been familiar in design forms of every scale, including, for example, in Ledoux's eighteenthcentury utopian urban visions. Yet while pyramids were perceived as massive and forbidding, the clarity and openness of I.M.'s Louvre pyramid sets it apart from nearly every other architectural pyramid and is the source of its magic. Along with the National Gallery, the John F. Kennedy Library, the John Hancock Tower, and his projects in China, the pyramid stands as a measure of not just I.M. Pei's talents but most impressively his patience, perseverance, and commitment to his own compass.

All these breath-taking achievements came after I.M. had already earned the (fifth) Pritzker Prize in 1983 . He used this prize money - $\$ 100,000$ - to establish a scholarship for Chinese architectural students. Yet again, he took the opportunity to be a mentor, and this time to students he would not even know.
I was even more fortunate than they were. I.M.'s mentoring to me was personal and, in the crucible of the studio, unforgettable in all the very best ways. I was out of graduate school for less than a year, and he took me under his wing. After only six months working in his office of then 160 people, he sent me to China to supervise the construction of Fragrant Hill. That's the architectural equivalent of being thrown into the deep end of the pool, and I didn't think I deserved his confidence. But he was with me every step of the way, and this is how I witnessed and learned from his example.

A few years later, when I finally summoned the courage to tell him that I was leaving to form my own practice, he reassuringly said I was ready and offered some of his most memorable advice: when considering commissions, always choose a curious and spirited client rather than a seductive project. Good advice, for that's what his own clients did: they chose a brilliant and intrepid architect, and fifty years of widely admired, pathbreaking projects speak for themselves. We stayed in close touch over the following thirty-five years. Ever generous, I.M. always insisted on treating me to lunch, where we would linger long over philosophical topics. Alas, our next lunch was on the calendar, and how I wish he hadn't slipped away just a few days before.

I.M Pei and Eileen Woo had four children, among whom the eldest, T'ing Chung Pei, died in 2003. He is survived by Chieng Chung Pei and Li Chung Pei, of Pei Partnership Architects, and Liane Pei, a lawyer.

Calvin Tsao is Partner in TsAO \& McKOWN Architects, based in New York Recent projects include Sangha, Suzhou; Brower Park Library, Brooklyn; and Sunbrella Headquarters, Burlington, North Carolina.

\section{Illustration credits}

arq gratefully acknowledges:

Dimitry B, 9

Elvert Barnes, 3

Alex Kisiel, 6

Bernard Spragg, 8

Calvin Tsao, 1, 2, 7

Christopher Woods, 4

Xiquinhosilva, 5 